\title{
Tracking the Course of Hippocampal Representations during Learning: When Is the Map Required?
}

\author{
Lesley A. Schimanski, Peter Lipa, and Carol A. Barnes \\ Evelyn F. McKnight Brain Institute, Arizona Research Laboratories Division of Neural Systems, Memory, and Aging, University of Arizona, Tucson, Arizona \\ 85724
}

Distinct ensembles of hippocampal cells can be active in numerous contexts, but specific "cognitive maps" tend to be retrieved on repeat visits to the same place. During aging, the reliability of map retrieval in CA1 networks is reduced; this provides a unique opportunity to investigate correlations between inconsistent activity patterns in circuits hypothesized to enable context encoding and hippocampusdependent learning ability. Here, CA1 pyramidal cells were recorded in six young and six old rats, while memory for specific locations was probed using a place-dependent eyeblink conditioning task. Rats were conditioned twice daily for 31 days, during which a total of 8259 and 7042 cells were recorded from young and old rats, respectively. Spontaneous remapping, a change in location of the majority of place fields between two consecutive sessions in the same environment, was observed in two young rats and four old rats during this task, but only after at least 13 days of training. Under these conditions the altered network representation did not result in loss of spatial accuracy of the blink, and in fact those rats with the best place conditioning remapped the most, whereas those with the best memory in a spatial water maze task remapped the least. These results suggest that when the hippocampal representation for a particular context is weak or unstable, such as can occur in senescence, extra-hippocampal systems that mediate alternate learning strategies are more likely to dominate behavior.

\section{Introduction}

Ensembles of hippocampal neurons with place-specific firing activity (place cells) are hypothesized to form a population code for a "cognitive map" of an environment (O'Keefe and Nadel, 1978). The locations in which place cells prefer to fire ("place fields") undergo refinement during the initial few minutes of exposure to a novel space (Hill, 1978; Wilson and McNaughton, 1993) and are typically retrieved when the environment is revisited on subsequent occasions. Field locations can remain stable for months in rats (Thompson and Best, 1990), and these lasting activity patterns may play a critical role in contextual or episodic memory (e.g., Moser et al., 2008). Sensory, behavioral, and motivational modifications can, however, elicit changes in locations or firing rates of most place fields (known as "remapping") (Leutgeb et al., 2005; Colgin et al., 2008). Place field locations can also shift when there are changes in task demands or "cognitive state" (Markus et al., 1995). Furthermore, changes in place field locations

\footnotetext{
Received March 19, 2012; revised Nov. 27, 2012; accepted Dec. 20, 2012.

Author contributions: L.A.S. and C.A.B. designed research; L.A.S. performed research; L.A.S. and P.L. analyzed data; L.A.S. wrote the paper.

This work was supported by McKnight Brain Research Foundation, National Institute on Aging Grant AG012609; Canadian Institutes of Health Research Grant SIB78537, and Alberta Heritage Foundation for Medical Research Grant 20060436. We thank Drs. Carolyn Harley, Bruce McNaughton, and Masami Tatsuno for their input into experimental design and methods. Brittanie Broersma, Joseph Bohanick, Alaina Glatting, Gabriela Fisher, and Andy Seymour contributed significantly to data collection, and Kim Bohne constructed the hyperdrives. Jie Wang, Jeri Meltzer, and Ana Egurrola assisted in unit data analysis, and Michelle Carroll and Luann Snyder assisted with manuscript preparation and administrative support.

Correspondence should be addressed to Carol A. Barnes, Evelyn F. McKnight Brain Institute, University of Arizona, Life Sciences North, Room 355, Tucson, AZ 85724-5115. E-mail: carol@nsma.arizona.edu.

DOI:10.1523/JNEUROSCI.1348-12.2013

Copyright $\odot 2013$ the authors $\quad 0270-6474 / 13 / 333094-13 \$ 15.00 / 0$
}

prompted by environmental manipulations result in predictable changes of spatial behavior (O'Keefe and Speakman, 1987; Lenck-Santini et al., 2001; Kubie et al., 2007), suggesting that adjustments of the hippocampal map are required for some types of spatial learning.

Indeed, plasticity within ensembles of hippocampal neurons undergoes age-related change that correlates with spatial memory impairments. Although many firing characteristics of single hippocampal cells remain intact in the aged rat (Shen et al., 1997; Burke and Barnes, 2008), some dynamics of spatial information processing are affected by age (Rosenzweig et al., 2003). For instance, Barnes et al. (1997) found that rats sometimes failed to retrieve a prior hippocampal map when they later revisited the same context, and this occurred more prevalently in aged rats than in young adult rats (Gerrard et al., 2001).

Here we address the question of how hippocampal place cells support different kinds of learning and how this support is influenced by age and map stability. To this effect we relate the results of three studies with the same cohort of young and aged rats: (1) an eyeblink learning task that explored spatial conditioning ability; (2) an electrophysiological study that looked at place fields and remapping during the eyeblink task; and (3) a Morris water task study that assessed spatial memory.

The combined results of these studies showed the following: (1) no difference between age groups in spatial eyeblink conditioning; (2) age impairment in spatial memory in the Morris water task; (3) reduced place field stability (more remapping) in aged rats. Most interestingly, place field stability correlated positively with spatial learning performance in the water maze learning but negatively with spatial eyeblink conditioning. These 


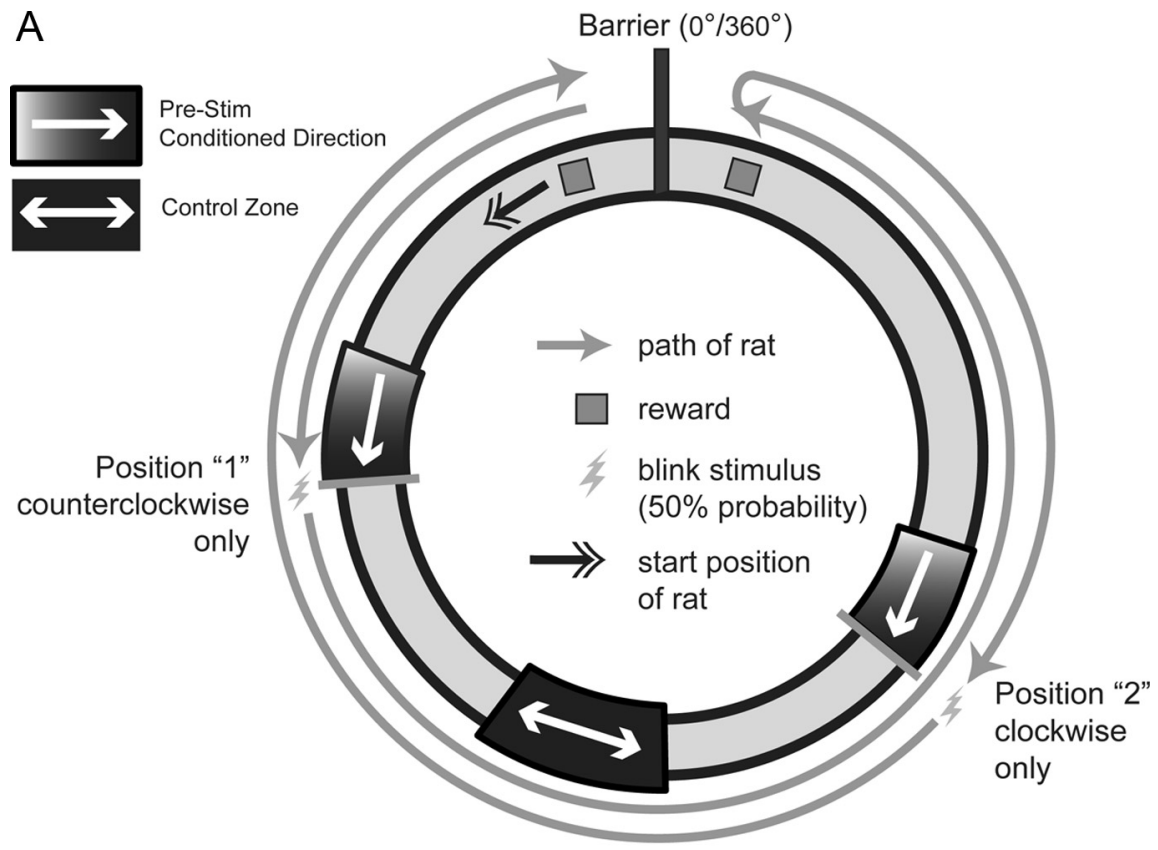

B

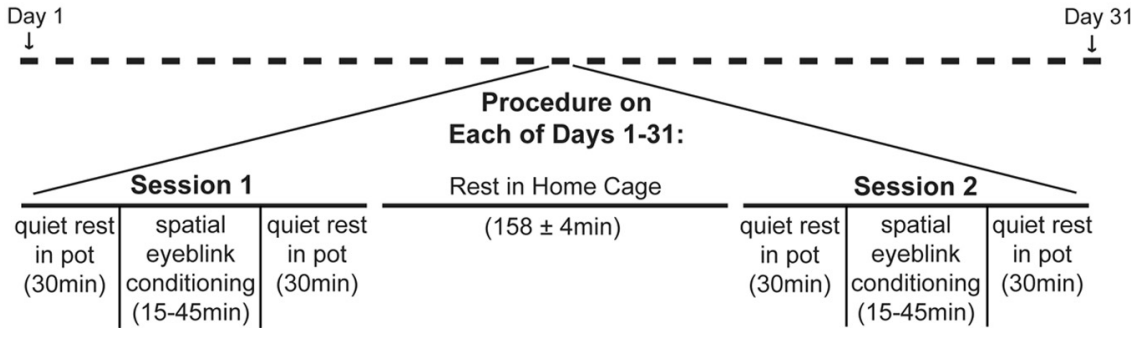

Figure 1. Spatial eyeblink conditioning task design. $\boldsymbol{A}$, Rats ran "horseshoe" pattern laps (alternating counterclockwise and clockwise directions) for food rewards located on either side of a barrier. After five laps in each direction, rats received electrical stimulation of the right eyelid on a 50\% pseudorandom schedule at Position 1 (counterclockwise running direction only) and Position 2 (clockwise running direction only) for another 32 laps in each direction. The locations of these positions were not indicated by discrete visual cues. EMG data from the right eyelid were analyzed for muscle contraction (blinking) during the last 20 $\mathrm{cm}$ of the counterclockwise approach to Position 1 and clockwise approach to Position 2 (Pre-Stim Conditioned Direction) using blinking activity in a region equidistant from positions 1 and 2 (Control Zone) as the control baseline. $\boldsymbol{B}$, Rats were trained in spatial eyeblink conditioning for 31 days. On each day, Session 1 consisted of a 30 min quiet rest in a pot, then spatial eyeblink conditioning as outlined in $A$, and then a second 30 min rest. After completion of Session 1, rats went to their home cage for a $2 \mathrm{~h}$ rest before returning to the recording room for Session 2, which was identical in procedure to Session 1.

findings suggest that whether or not a learning strategy depends on the hippocampus may be reflected in the hippocampal code.

\section{Materials and Methods}

Subjects and behavioral pretraining

Experiments were conducted on 11 young adult (9-12 months) and 10 old (25-28 months) male Fischer-344 rats obtained from the National Institute on Aging colony at Charles River. Rats were housed individually and maintained on a 12:12 h reversed light cycle. All experiments were performed following the guidelines of the United States National Institutes of Health Guide for the Care and Use of Laboratory Animals using protocols approved by the University of Arizona Institutional Animal Care and Use Committee.

Motor ability, vision, and spatial learning were tested using the Morris swim task (Morris, 1984) before the conduct of behavioral or electrophysiological experiments. Spatial (hidden platform) testing was administered over four consecutive days, with six training trials per day followed by visual assessment (visible platform). This testing was conducted for six trials per day for two consecutive days. Full details of the swim task are as described in full by Barnes et al. (1996).
After the swim task, rats were food deprived to $85 \%$ body weight and trained to run on a rectangular-shaped maze $(94 \times 80 \mathrm{~cm})$ for food reinforcement $(\sim 0.1 \mathrm{ml}$ chocolateflavored Ensure per lap). Rats ran in a horseshoe-type pattern in which food reward was given on one side of a barrier, after which rats turned around and ran around the rectangle to the other side of the same barrier to receive another reward. Training continued until rats completed 80 laps ( 40 each in the clockwise and counterclockwise directions) within 45 min. This typically required one or two training sessions per day of $15-60 \mathrm{~min}$ for $7-14$ days.

\section{Surgical and electrophysiological recording procedures}

The right eyelids of five young adult and four old rats were implanted with four insulated annealed 0.005 " stainless steel wires for monitoring of spatial eyeblink conditioning behavior. A second cohort of six young adult and six old rats received eyelid wire implantations as just described, and also the attachment of a hyperdrive manipulator device (Wilson and McNaughton, 1993) that holds an array of 12 independently adjustable tetrode recording probes (McNaughton et al., 1983b; Recce and O’Keefe, 1989).

Rats began a 10 day cycle of ampicillin or a 5 day cycle of sulfamethoxazole and trimethoprim oral suspension the day before surgery. Rats were anesthetized using 1.0-2.0\% isoflurane in oxygen (flow rate $1.5 \mathrm{~L} / \mathrm{min}$ ) and were then placed into a stereotaxic apparatus. During surgery, insulation was stripped from 2 $\mathrm{mm}$ tips of wires that were embedded subcutaneously in the eyelid. Two of these wires were later used to deliver bipolar electrical stimuli, and the other two to differentially record electromyographic (EMG) data from the eyelid. A ground screw was placed in the skull, and all wires were fitted into an adapter that was secured to the skull using screws and dental acrylic.

The hyperdrive was positioned over a craniotomy centered $2.0 \mathrm{~mm}$ lateral (right hemisphere) and $3.8 \mathrm{~mm}$ posterior to bregma. Tetrodes were constructed of four polyimide-coated nichrome wires (13 $\mu \mathrm{m}$ diameter) that were twisted together. The 12 tetrodes were placed at a depth of $\sim 1 \mathrm{~mm}$ at surgery and were slowly moved ventrally over the next 14 days to record spikes extracellularly from the CA1 pyramidal cell layer of the dorsal hippocampus (at $\sim 2000 \mu \mathrm{m}$ from the brain surface). Two additional tetrodes, in which the four wires had been shorted together, served as references and were placed in or near the corpus callosum and hippocampal fissure, respectively. Signals from the 12 tetrodes were differentially recorded with respect to the electrode in or near the corpus callosum. Rats continued pretraining during the 14 days of recovery and tetrode adjustment, and recording of CA1 activity and spatial eyeblink conditioning began when clear CA1 action potentials were present on most tetrodes. After recording began, tetrodes were moved when necessary to optimize spike signals. If tetrodes were moved, they were only adjusted after recording on a given experimental day to allow stabilization for $18 \mathrm{~h}$ before the next recording. Because on average only $18 \%$ of tetrodes were moved each day, it is possible that the same cells were recorded on multiple days of the experiment.

The four channels of each tetrode were each connected to a separate channel of a 54 channel unity-gain headstage that was adorned with 
LEDs and connected via shielded wires to programmable amplifiers (Neuralynx). Video data obtained via a black-and-white overhead CCD camera and electrophysiological data were digitized and recorded by the Cheetah Data Acquisition System (Neuralynx). Spike signals were digitized at $32 \mathrm{kHz}$, amplified 500 to $5000 \times$, and bandpass filtered between $600 \mathrm{~Hz}$ and $6 \mathrm{kHz}$. Events that reached a custom-set threshold (typically 5-20 $\mu \mathrm{V}$ ) above the level of baseline noise were recorded for a $1 \mathrm{~ms}$ duration. Eyelid EMG signals were bandpass filtered between $300 \mathrm{~Hz}$ and $3 \mathrm{kHz}$, sampled at $1900 \mathrm{~Hz}$, and amplified by the unity-gain headstage and adjustable amplifiers (typically $500-1000 \times)$.

\section{Behavioral procedures}

On day 1 of the spatial eyeblink conditioning experiment, rats were removed from their home cages in the colony and taken to a dedicated room to determine the level of current required to induce an eyeblink. The eyelid stimulus was a $100 \mathrm{~ms}, 100 \mathrm{~Hz}$ train of bipolar square pulses $5 \mathrm{~ms}$ in duration delivered through two of the wires implanted in the right eyelid using a Master-8 from A.M.P.I. and stimulus isolator A365 from World Precision Instruments. Each day before training, the current was adjusted to elicit a complete eye blink (typical range, 0.1-0.6 mA).

After calibration of the eyeblink current, rats were brought to the experiment room where recordings took place. This recording room (dimensions $3.05 \times 3.82 \mathrm{~m}$ ) contained a table on which a circular track $(85 \mathrm{~cm}$ diameter) rested and a towel-lined clay flowerpot stood. The room was dimly lit with a desk lamp directed toward one corner, and numerous visual cues (e.g., a large electronics rack, a shelving unit, a door painted in a darker color, a picture on the door) were present along the perimeter. On the first recording day the room was completely novel. Rats were connected to the Cheetah recording system (Neuralynx) via tethered headstage and placed into a pot to rest quietly alone in the room for a minimum of 30 min before conditioning trials were initiated.

After this quiet resting period, an experimenter entered the room and placed the rat onto a circular track $(85 \mathrm{~cm}$ diameter) next to a barrier facing toward the counterclockwise direction as shown in Figure $1 A$. The pot was then placed out of sight on the floor. Rats ran five counterclockwise and five clockwise laps (alternating in direction) for food rewards near either side of the barrier. Starting on lap 11, eyeblink stimuli were delivered on a $50 \%$ pseudorandom schedule at two unmarked positions on the track (see Fig. $1 A$ for configuration). Delivery of eyeblink stimuli was also direction specific in that stimuli at "Position 1" occurred only while the rat ran in the counterclockwise direction, and at "Position 2 " only in the clockwise direction. The reason for including stimuli in two different directions is because on linear tracks CA1 pyramidal cells tend to show independent hippocampal maps depending on direction of movement (McNaughton et al., 1983b). By including stimuli in both running directions, the study of the relationship between stimulus location and hippocampal map characteristics is maximized within the experiment. Rats ran laps until they reached a 74 lap total (10 laps with no eyeblink stimuli plus 64 laps with 50\% eyeblink stimuli) or until they ceased locomotion. Young adult and old rat pairs served as yoked controls to match the number of laps run per session between age groups. If one rat of a pair was identified as a weak runner and did not reach the 74 lap goal, it was tested first. The second rat of the pair was subsequently
B

Rat 8417: Day 13, Tetrode 01

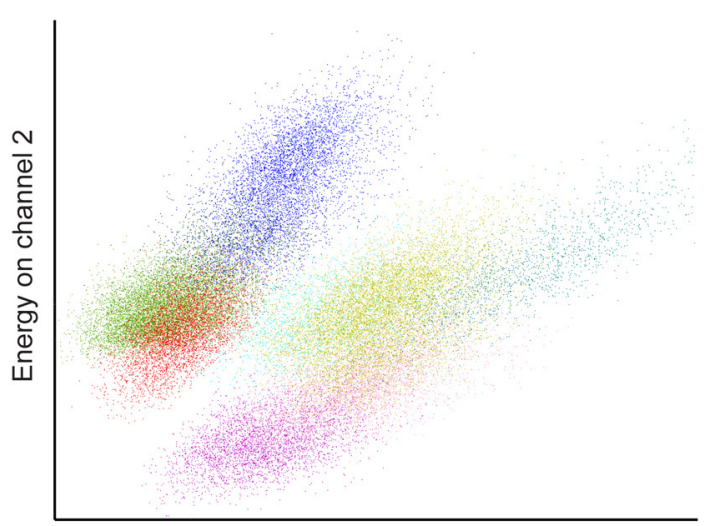

Energy on channel 1

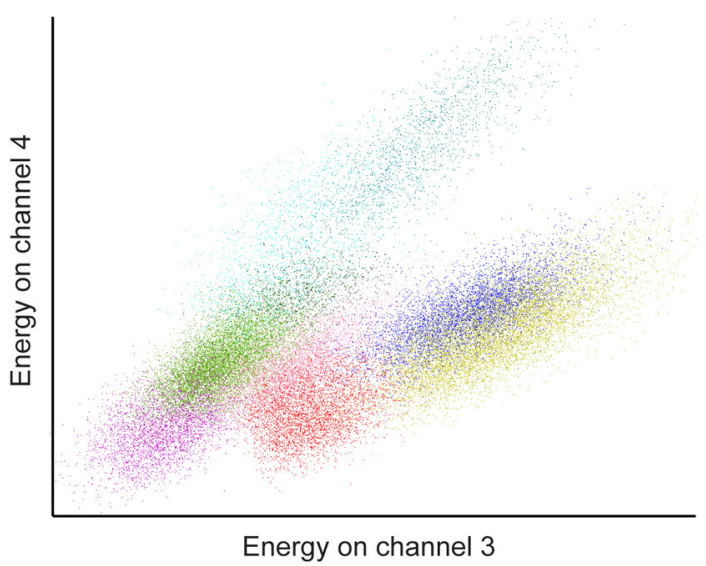

Figure 2. Representative electrophysiological data recorded from one tetrode during a single spatial eyeblink conditioning session. $A$, The mean and standard error of the mean of spike wave shapes of nine putative single cells. A $1 \mathrm{~ms}$ sample of the average with each data point representing energy (square root of the sum of the squared spike amplitudes) from each putative cell. Each cluster is assigned a unique color, matching that of the waveforms shown in $\boldsymbol{A}$.

allowed to run the same number of laps as that reached by the first rat. This procedure was adopted such that both groups received approximately the same number of eyeblink stimuli. Rats were then placed back in the pot on the table to rest quietly alone in the room for another 30 $\min$.

Rats were then removed from the recording system and taken back to their home cages for an average of $157.5 \pm 4.0 \mathrm{~min}$ before completing a second training session in the same room as the first training session, following the same methodology. This training protocol was repeated for 31 days in the same room (see Fig. $1 B$ for a schematic of the experimental design).

\section{Data analysis}

One old rat became ill after 15 days of spatial eyeblink conditioning and failed to complete the full experiment; his first 15 days of data have been included in the analyses. There was also one young rat from which not enough units were recorded on day 24 of the experiment to reliably assess the stability of the spatial map; this day was excluded from remapping analyses.

Morris swim task. Performance on the spatial and cued version of the swim task was analyzed using custom software (WMAZE, M. Williams) or a custom add-on to Any-maze (Stoelting) as described previously (Shen and Barnes, 1996). The WMAZE and Any-maze analyses both calculated a corrected integrated path length (CIPL; Gallagher et al., 1993) for all spatial and visual trials. CIPL, rather than latency, is reported to avoid the variability in results introduced by differences in swimming 


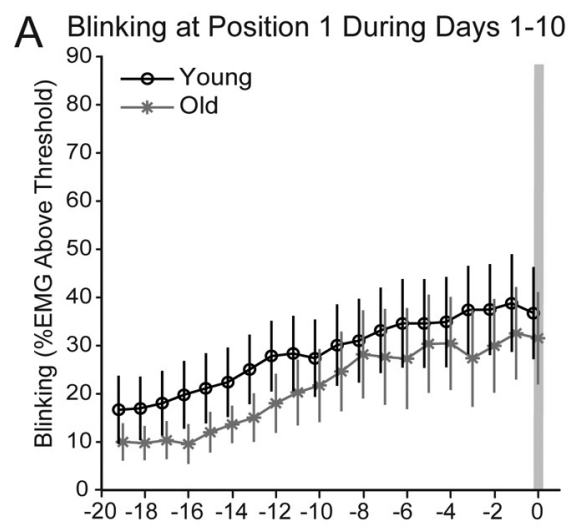

C Blinking at Position 2 During Days 1-10
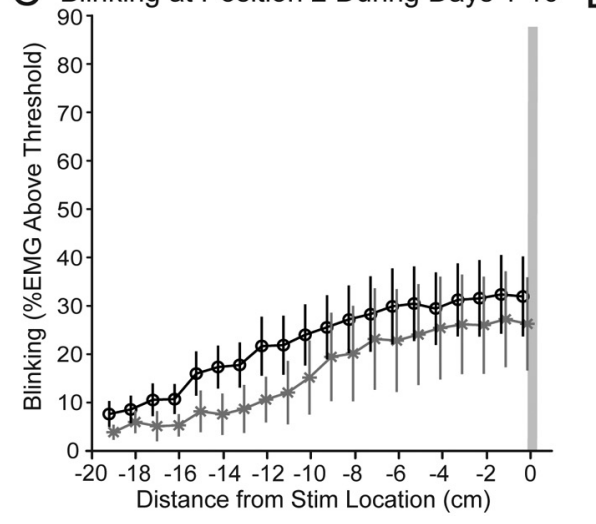

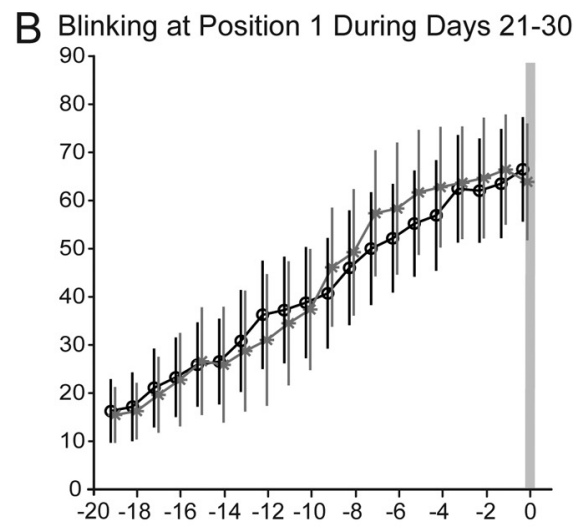

Blinking at Position 2 During Days 21-30

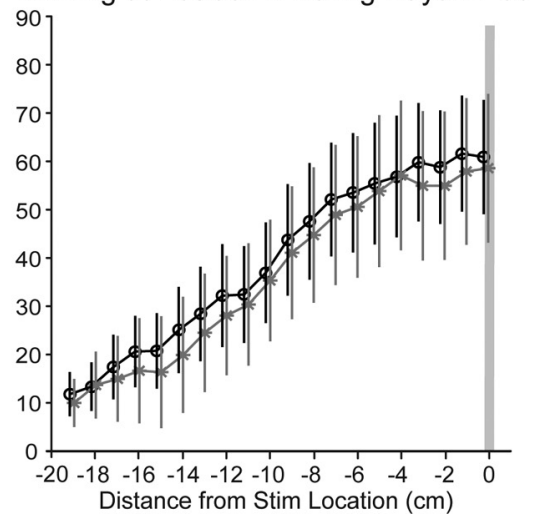

Figure 3. Blinking increases as rats approach the eyeblink stimulus positions. $A, C$, Stimuli were delivered at $0 \mathrm{~cm}$ on the $x$-axis (gray vertical bar). A modest increase in blinking as rats run toward the stimuli is evident during days 1-10 at both Position $1(\boldsymbol{A})$ and Position $2 \boldsymbol{B}, \boldsymbol{D}$, Blinking increases to a higher level during days $21-30$ near both positions $(\boldsymbol{B}, \boldsymbol{D})$. There were no significant differences in blinking levels between age groups, but a significant effect of distance from stimulus location in all plots (see Statistical analyses, Materials and Methods). Days 1-10: Young, $n=11 ; 0$ ld, $n=10$. Days 21-30: Young, $n=9 ;$ Old, $n=9$. Data shown in this and subsequent figures are mean \pm SEM.

speed and release locations. A water maze index was calculated from CIPL values for each trial by assigning an index of 10 when the CIPL score was $<50 \mathrm{~cm}$. When the CIPL score was $>50 \mathrm{~cm}$, the index declined by 1 for each $50 \mathrm{~cm}$ the CIPL score increased. The minimum index score possible was 1 for CIPL values $>450 \mathrm{~cm}$.

EMG analysis. Portions of the raw EMG signal containing stimulus artifacts were removed using recorded timestamps of the delivery of the stimuli. The raw EMG signal was rectified and smoothed by taking the difference between the maximum and minimum signal amplitude in a sliding $20 \mathrm{~ms}$ window, and the resultant signal was resampled every 0.01 $\mathrm{cm}$. The mean and standard deviation of the smoothed and resampled EMG signal in a $22.5 \mathrm{~cm}$ "control" region of the circular track centered an equal distance from both stimulus positions and opposite from the rewards and barrier were calculated (both clockwise and counterclockwise running directions were included). The $20 \mathrm{~cm}$ portion of the maze adjacent to the stimulus positions were expressed as $Z$-scores, calculated using the mean and standard deviation from a control region equidistant from the two stimulus locations. The percentage of points with a value greater than a threshold equal to a $Z$-score of 3 was calculated for $1 \mathrm{~cm}$ segments. The clockwise/counterclockwise running directions were analyzed separately except for within the control zone; regions of the circular track analyzed are shown in Figure $1 A$.

Analysis of spike data. To avoid potential unreliability in tracking single cells over multiple recording sessions, spike data from the two recordings of each day were pooled before analysis. Spikes were sorted into clusters using an automated algorithm (KlustaKwik, K. D. Harris, Rutgers University, Newark, NJ) and then manually refined using MClust (A. D. Redish, University of Minnesota, Minneapolis, MN) and Waveform Cutter (S. L. Cowen, Neurosciences Institute, San Diego, CA). Figure 2 shows a representative example of spike waveforms on each channel of the tetrode for each cell and corresponding clusters used during spike sorting. For all analyses reported here, only units that were active $(>0.01 \mathrm{~Hz}$ firing rate) during all four rest periods of the experiment day and fired at least 30 action potentials during sessions 1 and 2 of eyeblink conditioning were included, and units with an average firing rate $>4 \mathrm{~Hz}$ during track running were not included. Data collected during periods when rats were moving at a velocity of $6 \mathrm{~cm} / \mathrm{s}$ or lower were removed from analysis to exclude action potentials coincident with sharp wave ripples that can occur in the absence of locomotion.

Video data were smoothed and an algorithm was applied to determine the position of the rat (location of LED headstage lights) at all time points using a polar coordinate system. The angular coordinate of the rat was used to "linearize" the circular track in the two running directions. Using the timestamps of the spikes and smoothed video tracker data, the location of the headstage on the linearized track at the time of each spike was determined. Firing rates were calculated for $10^{\circ}(7.4 \mathrm{~cm})$ segments of the circular track for each training session, and any segments not visited during the session were excluded from the analysis. These rate maps were smoothed using a 5 point Hanning window. Place fields were then determined on the basis of the rate map averaged over the whole running session. They were defined by finding the locations of peaks in firing rate $>2$ $\mathrm{Hz}$ with $0.5^{\circ}$ precision (this method is similar to that used by Shen et al., 1997 and Henriksen et al., 2010). Place field boundaries were set where the firing rate fell below $10 \%$ of the local peak rate on either side of the peak, and fields that did not exhibit place-specific activity patterns (diameters $>85 \mathrm{~cm}$, the size of the circular track) were not included in the analysis.

Spatial correlation scores were calculated for each recorded unit as the Pearson correlation coefficient of firing rate maps between training sessions 1 and 2 on each day. For analysis of place field location matching, a place field in Session 1 was matched with a place field in Session 2 of the same day if both were recorded from the same putative unit and if the center of mass of one field in Session 1 fell within the boundaries of the field in Session 2, or vice versa. Rate overlap scores were calculated for each unit by dividing the higher of its mean firing rates during conditioning sessions 1 or 2 by the lower of those two rates. To calculate the normalized rate difference for each place field on each day, the integral (area) of the average firing rate map within the boundaries of the field was determined for Session 1. This integral was calculated also for Session 2 using the same place field boundaries. The absolute value of the difference between these integrals was divided by their sum to yield the normalized rate difference for that place field.

Statistical analyses. The normality of data distributions was assessed using the Shapiro-Wilk test (MATLAB or SPSS, version 17) before further analysis. Alpha levels of 0.05 (two-tailed) were used throughout, except when specified otherwise. When data were distributed normally and acquired over several positions or multiple training sessions, repeated-measures ANOVA was used to compare age groups. If data were not distributed normally, three statistical assessments were carried out: (1) data were collapsed over sessions or positions, the resultant distribution was assessed for normality, and then Student's $t$ test or the Mann-Whitney $U$ test were calculated; (2) individuals were randomly assigned to the two age groups in 25 to 100 permutations, and the resul- 
tant repeated-measures ANOVA $p$ values for the factor of age and the interaction of age with position or session were calculated for each permutation. The $p$ values calculated using the actual age group assignments were compared to those calculated using the random permutations. If the true $p$ value was less than the fifth percentile of the distribution, the age or interaction effect was considered significant; (3) Friedman's test was calculated to assess whether there was a significant effect of position or session over the repeated measures. When age groups were not significantly different as assessed in (1) or (2), groups were collapsed. When age groups were significantly different, Friedman's test was calculated for each, and the Bonferroni adjustment was used.

\section{Results}

Study 1: spatial eyeblink conditioning Following recovery from surgery to implant eyelid wires (and also implant hyperdrives in six rats in each of the young and old groups), rats were trained in the spatial eyeblink conditioning task for 31 days as described in Figure 1. As shown in Figure 3, $A$ and $C$, EMG activity increased significantly in both age groups over the $20 \mathrm{~cm}$ approach to the stimulus locations during days 1-10 of training (Position 1, Friedman test (effect of distance from stimulus): $\chi^{2}(19)=63.492, p<0.001$; Position 2, Friedman test (effect of distance from stimulus): $\chi^{2}(19)=110.298$, $p<0.001)$. EMG activity increased significantly and to higher levels in both age groups during days 21-30 of training (Fig. $3 B, D$; Position 1, Friedman test (effect of distance from stimulus): $\chi^{2}(19)=$ 221.768, $p<0.001$; Position 2, Friedman test (effect of distance from stimulus: $\left.\chi^{2}(19)=234.723, p<0.001\right)$. There were no significant differences in EMG activity between age groups during days 1-10 or days 21-30 of training. On trials in which no eyeblink stimuli were given, young and old rats exhibited a similar decay in blink activity as they left the stimulus positions (data not shown), indicating that there was no effect of age on accuracy of the blink response.

Next, to examine rats' rate of learning, the percentage of EMG activity above threshold was calculated for the last $4 \mathrm{~cm}$ of the approach to the stimulus locations from the conditioned direction for individual training sessions. As shown in Figure 4, $A$ and $B$, blinking near the stimulus positions increased significantly during training (Position 1, Friedman test (effect of training): $\chi^{2}(61)=141.569, n=14, p<0.001$; Position 2, Friedman test (effect of training): $\chi^{2}(61)=144.032, n=14, p<0.001$ ). Although aged rabbits require more training trials to acquire trace eyeblink conditioning than do younger rabbits (Moyer et al., 2000), old rats in the present study, using the place conditioning procedure, did not differ in performance at either stimulation position when data were collapsed over all days of training (Position 1, Student's $t$ test: $t_{(19)}=0.58, p=0.569$; Position 2, Stu-
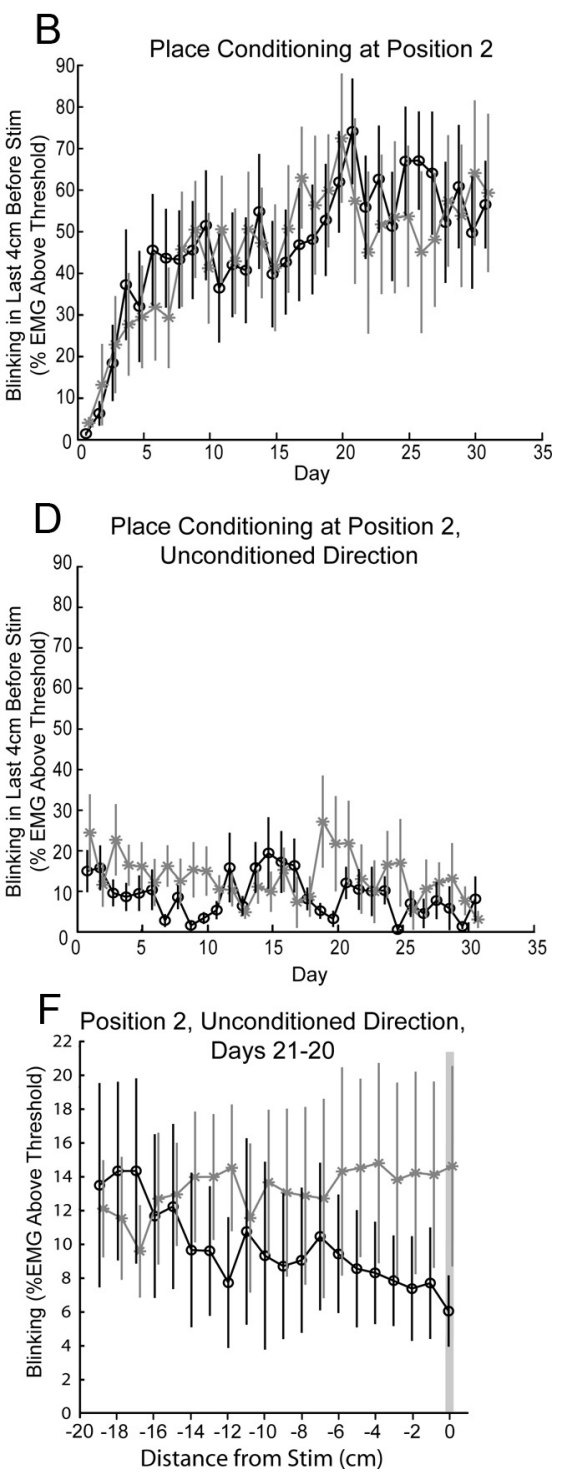

Figure 4. Young and old rats learn the locations of eyeblink stimuli (Stim). $\boldsymbol{A}, \boldsymbol{B}$, In the conditioned running direction as rats approach Position $1(\boldsymbol{A})$ and Position $2(\boldsymbol{B})$, blinking levels (mean percent EMG above threshold) within the $4 \mathrm{~cm}$ closest to the blink shown within the $4 \mathrm{~cm}$ closest to Position 1 (C) and Position 2 (D).E, F, Data from days 21-30 are combined to illustrate that old rats increase blinking levels as they approach Position $1(\boldsymbol{E})$ but not Position $2(\boldsymbol{F})$ from the unconditioned direction; young, $n=11 ;$ old, $n=10$. Of these, 8 young and 7 old rats completed all 31 days of training; all rats completed training to at least day 14 .

dent's $t$ test: $\left.t_{(19)}=0.416, p=0.682\right)$. Furthermore, the number of trials required for young and old rats to acquire spatial eyeblink conditioning in the present study was similar to that required for young rats to acquire a trace eyeblink conditioning problem (Green and Arenos, 2007). To assess whether blinking patterns of rats were different during the first 10 laps when no eyeblink stimuli were given, blinking in the prestimulus zone was analyzed during this period. Over days 1-31 there were no age differences in blinking during the first 10 laps of each session (Position 1, Student's $t$ test: $t_{(19)}=0.604, p=0.55$; Position 2, Mann-Whitney test: $Z=-1.41, p=0.159, n=21)$. Rats blinked significantly less during the first 10 laps compared to after the first eyeblink stimuli were given (Position 1, paired $t$ test: $t_{(20)}=3.75, p=$ 0.001; Position 2, Wilcoxon signed ranks test: $Z=-2.59, p=$ $0.01)$.

To assess whether rats learned to discriminate between the conditioned and unconditioned directions of running at posi- 


\section{A Rat 8419, Day 15, Morning Session}

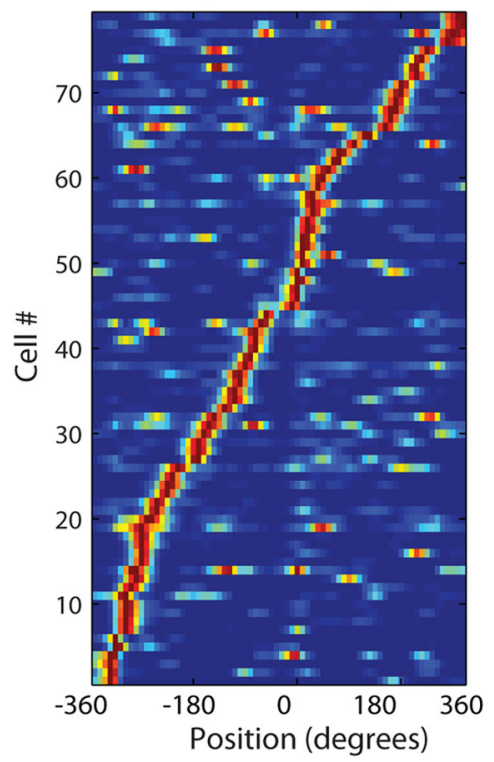

B Rat 8419, Day 14, Morning Session

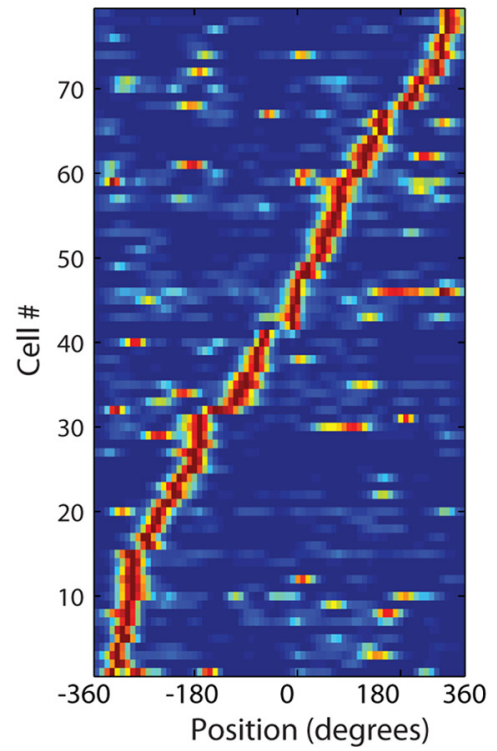

Rat 8419, Day 15, Afternoon Session

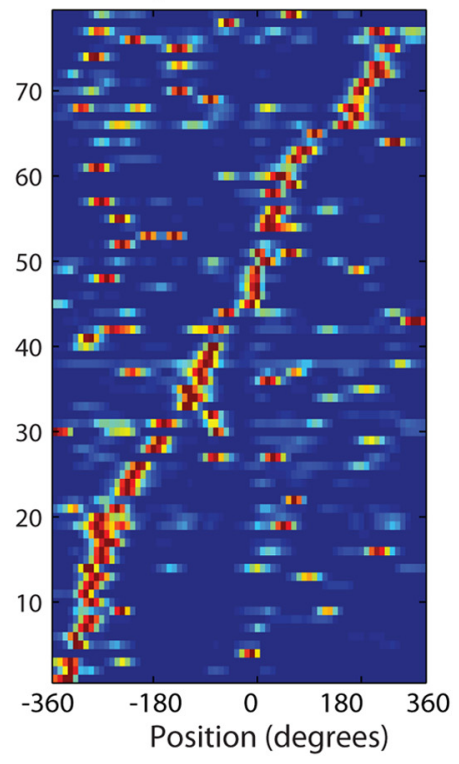

Rat 8419, Day 14, Afternoon Session

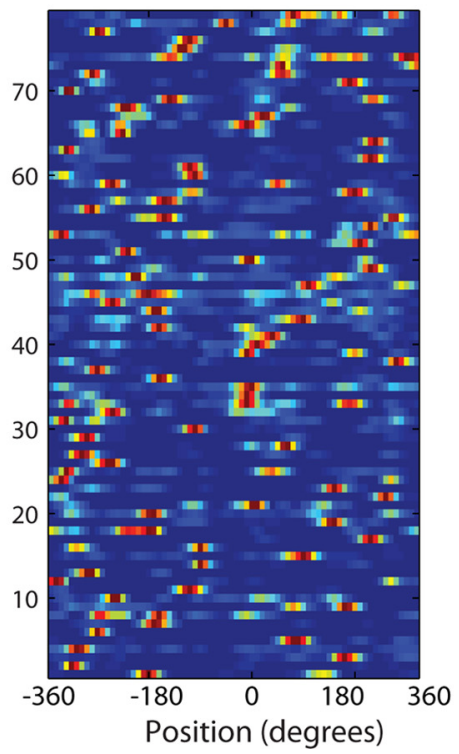

Figure 5. Firing rate with respect to location in all place specific cells recorded from one rat on a day in which the hippocampal map was stable $(\boldsymbol{A})$, and another day on which spontaneous remapping occurred $(\boldsymbol{B})$. Each row represents the firing pattern of a cell normalized such that the peak rate is set to a value of 1 (red), and blue colors indicate the firing rate is zero. Columns represent position in $10^{\circ}$ segments $(7.4 \mathrm{~cm}$ bins); negative and positive degrees correspond to counterclockwise and clockwise running directions, respectively, and $0^{\circ}$ marks the barrier. The firing patterns of all cells recorded in the morning session (left) were ordered by location of the peak firing rate along the track. The firing patterns in the afternoon session (right) on the same day are shown with identical cell ordering to the morning session (left).

tions 1 and 2, blinking near the stimulus locations as rats approached from the unconditioned direction was measured. As shown in Figure 4, $C$ and $D$, rats blinked less in the unconditioned direction than in the conditioned direction at both positions 1 and 2. Blinking levels did not change significantly during training in young rats (Position 1, Friedman test (effect of training): $\chi^{2}(61)=70.174, n=8, p=0.197$; Position 2, Friedman test (effect of training): $\chi^{2}(61)=57.283, n=8, p=0.611$ ) and old rats (Position 1, Friedman test (effect of training): $\chi^{2}(61)=$ $66.668, n=6, p=0.288$; Position 2, Friedman test (effect of training): $\left.\chi^{2}(61)=48.926, n=6, p=0.867\right)$. However, there was more blinking in old rats than in young rats while approach-

ing Position 1 from the unconditioned direction (Mann-Whitney test: $\mathrm{Z}=$ $-2.183, p=0.029, n=21)$, but not Position 2 (Mann-Whitney test: $\mathrm{Z}=-0.775$, $p=0.439, n=21)$. Figure $4, E$ and $F$, illustrate that blinking increases as old rats approach Position 1 during days 21-30 of training. This is not observed at Position 2 in old rats, nor in young rats at either blink position.

\section{Study 2: stability of the hippocampal map}

As shown by Barnes et al. (1997), the CA1 population code for space sometimes spontaneously remaps in old rats even when no change to the environment occurs. This spontaneous remapping was observed in data collected in the present study as well (Fig. 5B shows an example of when remapping occurred between the first and second session of the day). To quantify the stability of spatial firing patterns in the CA1 hippocampal ensemble between sessions on each day of training, a spatial correlation score between the rate map from the first and second session of each day was calculated for all cells recorded from the six young and six old rats that received hyperdrive implantation. Typical values ranged from -0.2 (e.g., location of place field changed between sessions) to nearly 1.0 (place field location and rate were virtually identical between sessions). A frequency histogram of the average spatial correlation scores over all cells per session for all rats on all days of the experiment shows that on most days the average is $>0.6$, indicating that the ensemble map is spatially stable (Fig. 6 A). An overall spatial correlation score collapsed over all training days was calculated for each rat (mean of young adult rats: $0.694 \pm 0.026$; mean of aged rats: $0.608 \pm 0.052$ ), and there was no significant difference between age groups (Student's $t$ test: $\left.t_{(10)}=1.476, p=0.171\right)$. The percentage of cells exhibiting a spatial correlation score $<0.3$ (spatially unstable cells) was also calculated for each day; these data are reported in a frequency histogram in Figure 6B. An average percentage of unstable cells for all training days was calculated for each rat (mean of young rats: $15.32 \pm 2.65$; mean of old rats: $23.22 \pm 5.79$ ), and there was no significant age difference (Mann-Whitney $U$ test; $Z=-1.121$, $p=0.262$ ).

Next, place field locations were "matched" between the first and second recording session of each training day to determine whether each field of a unit was stably expressed in a similar location during both sessions. The distribution of the percentage of matched fields in each session is shown in Figure $6 C$ for young and old rats. Although there is no age difference in the mean percentage of matched fields collapsed over all sessions (young 

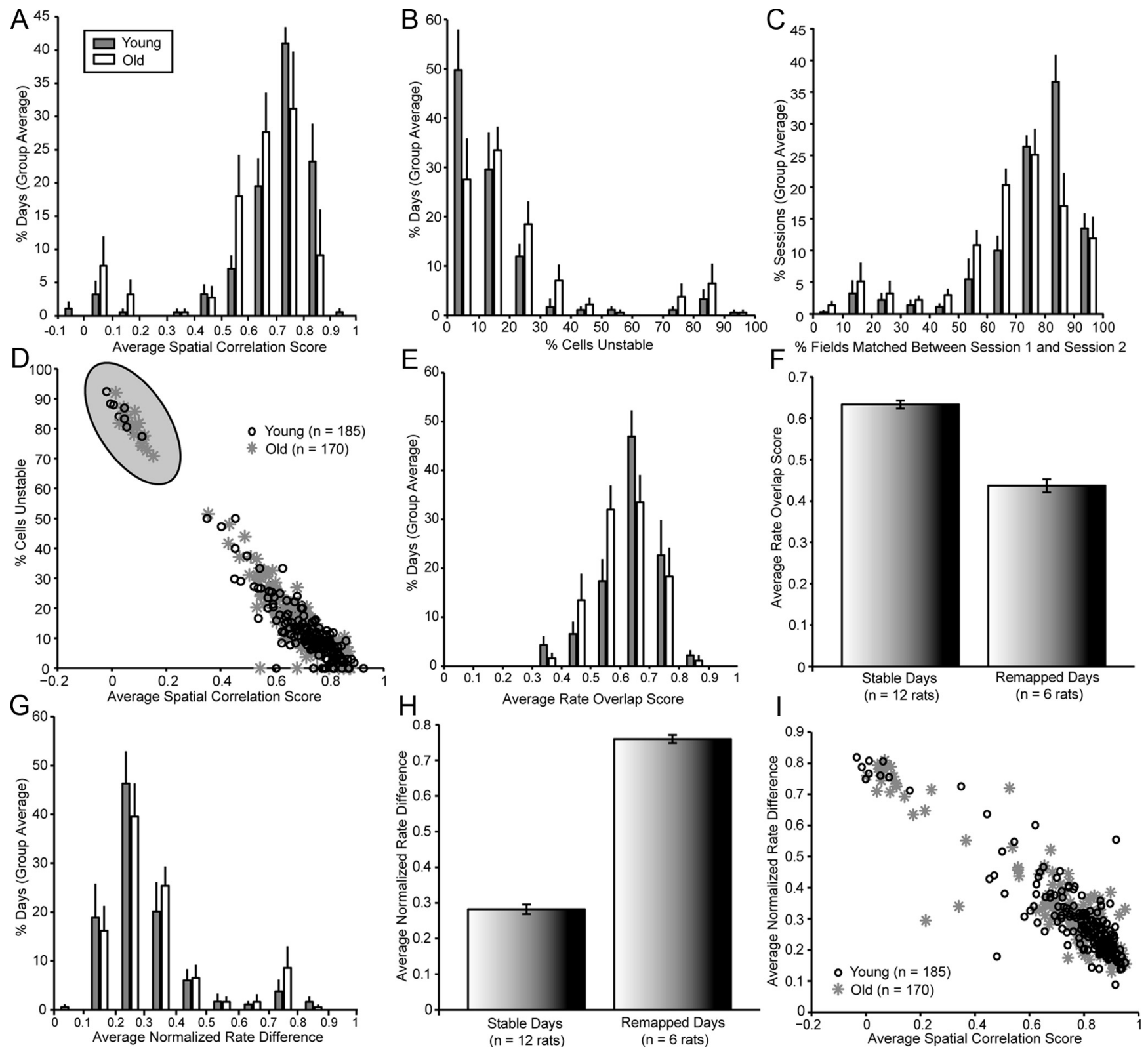

Figure 6. Spatial stability characteristics of the CA1 population code. $A-C$, Spatial stability of place cell firing was assessed on each day by calculating the average spatial correlation score between sessions $(\boldsymbol{A})$, the percentage of cells that have unstable spatial firing patterns between sessions (spatial correlation score $<0.3)(\boldsymbol{B})$, and the percentage of place fields that remained in the same position between Session 1 and Session 2 (C).D. Considering data from all training days, the average spatial correlation score and percentage of cells with low spatial correlation scores are negatively correlated with each other $(\boldsymbol{D} ; r=-0.970, p<0.001)$. Using nearest neighbor cluster analysis, each day was classified as "remapped" (points within gray zone) or "stable" (remaining points). $\boldsymbol{E}$, $\boldsymbol{H}$, Rate coding was assessed for each rat on each training day using two methods. $\boldsymbol{E}, \boldsymbol{F}$, First, the average rate overlap of all cells between conditioning sessions 1 and 2 was calculated. Similar rate overlaps are seen in young and old rats. The average rate overlap score was significantly lower on days in which rats remapped compared to stable days. $\boldsymbol{G}, \boldsymbol{H}$, Second, normalized rate differences were calculated for all cells between sessions 1 and 2 in both age groups. The frequency distribution of average normalized rate differences was similar between age groups. Remapped days had significantly higher average normalized rate differences than did spatially stable days. I, Normalized rate differences were negatively and significantly correlated with average spatial correlation scores. Young, gray bars, $n=6$; Old, white bars, $n=6$; bars are mean \pm SEM.

adults: $74.68 \pm 2.57$; aged adults: $67.38 \pm 4.56)$, repeatedmeasures ANOVA showed a significant interaction of age with the distribution of percent matched fields (age: $F_{(1,90)}=0.652$, $p=0.438$; percent matching fields: $F_{(9,90)}=26.22, p<0.0001$; age ${ }^{*}$ ) percent matching fields: $\left.F_{(9,90)}=4.02, p=0.0002\right)$. These data indicate that overall there is less precision in field location matching in the aged cohort.

To identify the days on which spontaneous remapping occurred in each rat, we examined the relationship between the average spatial correlation score and the percentage of spatially unstable cells on each day. As illustrated in Figure $6 D$, these mea- sures were significantly and negatively correlated (Pearson correlation: $r=-0.970, p<0.001$ ). The data points fell into two groups that were separated into "stable" and "remapped" days using nearest neighbor cluster analysis. Nine of 186 training days exhibited spontaneous remapping in young rats, and 20 of 170 days in old rats. Place field expression was spatially stable within recording sessions on both spatially stable and remapped days, and spatial stability did not appear to be affected by the tetrode depth adjustments made after recording on days in which it was necessary to seek more units (Fig. 7). There were also no significant differences between spatially stable and remapped days in 

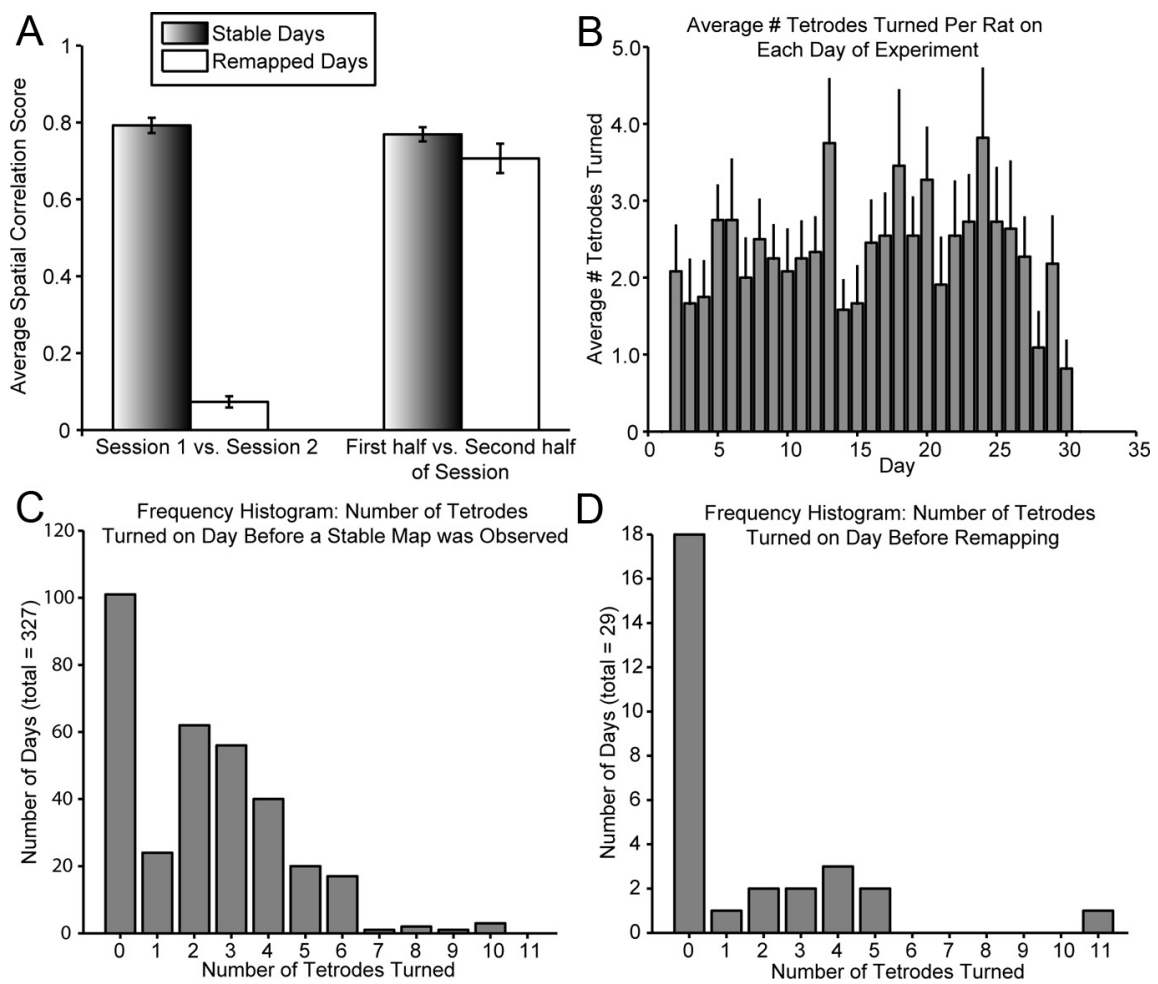

Figure 7. Remapping is not associated with changes of spatial firing patterns within recording sessions nor adjustments of tetrode position. $\boldsymbol{A}$, As a control to assess whether maps are stable within the sessions that occurred on remapping days, spatial correlation scores were calculated in two ways: (1) as in Figure 6D, between Training Session 1 and Training Session 2 on each day ("between sessions"); and (2) as a control, between the first and second half of each training session (excluding the first five laps in each direction with no eyeblink stimuli; "within sessions"). These values are reported independently for spatially stable and remapped days of the experiment. For spatial correlation scores calculated between sessions (left bars), on spatially stable days the average value was $0.792 \pm 0.02$ ( $n=12$ rats), and on remapped days it was $0.073 \pm 0.015$ ( $n=6$ rats). These values correspond to the mean of the average spatial correlation scores of each cluster in Figure $6 D$ and were significantly different from each other (Wilcoxon Signed Ranks Test: $Z=-2.201, p=0.028$ ). For the control, spatial correlation scores calculated within sessions (right bars), the average value on spatially stable days was $0.769 \pm 0.019$ ( $n=12$ rats), and on remapped days it was $0.707 \pm 0.038$ ( $n=6$ rats). These values are not significantly different (Wilcoxon Signed Ranks Test: $Z=-1.572 ; p=0.116$ ). Therefore, spatial firing patterns are no less stable within remapped sessions compared to spatially stable sessions. $\boldsymbol{B}$, Typically, the depth of two or three tetrodes (of a total of 12 tetrodes) was adjusted (or "turned") per rat per day of the spatial eyeblink experiment. C, D, To address the possibility that tetrode depth adjustment might elicit recording instability that could account for remapping, the number of tetrodes that underwent depth adjustment was calculated for days preceding spatially stable CA1 maps (C, 327 days of experiment) versus days preceding remapping ( $\boldsymbol{D}, 29$ days of experiment). Tetrodes were never turned immediately before recording sessions, and relatively few tetrode adjustments were made on the majority of days that preceded remapping.

the duration spent in the home cage between sessions 1 and 2, the length of the conditioning sessions, or the number of units recorded (Table 1).

Rate overlap scores (Leutgeb et al., 2006) were calculated for each unit to assess whether firing rates during spatial eyeblink conditioning differed between sessions 1 and 2 of each day. Rate overlap scores range from 0 to 1 , with lower numbers indicating large changes in firing rate and higher numbers indicating similar firing rates between sessions. An average rate overlap score was calculated for each rat on each day of the experiment, and these scores ranged from 0.318 to 0.877 ; these data are plotted in a frequency histogram in Figure $6 E$. When averaged over all days, the mean rate overlap score for young rats was $0.635 \pm 0.018$ and for old rats it was $0.604 \pm 0.014$, but there was no significant difference between age groups $\left(t_{(10)}=1.344, p=0.209\right)$. Over all days of the experiment the mean rate overlap score on stable days was $0.633 \pm 0.01$ and on remapped days it was $0.437 \pm 0.016$ (Fig. $6 F$ ). A paired $t$ test showed that rate overlap scores on stable days were significantly higher than those on remapped days $\left(t_{(5)}=9.34\right.$, $p<0.001$; analysis was restricted to six rats with both stable and remapped days in their datasets).

To assess rate coding within place fields, a normalized rate difference was calculated for each field on each day of the experiment (see Materials and Methods for formula). Normalized rate differences are close to 0 when the firing rate within the field is similar between sessions 1 and 2 , and the maximum possible value is 1 . An average normalized rate difference was calculated for each rat on each day of training; the scores ranged from 0.088 to 0.819 , and these data are plotted in a frequency histogram in Figure 6G. Averaged over all days, the mean normalized rate difference was $0.297 \pm 0.025$ for young rats and $0.332 \pm 0.039$ for old rats, and there was no significant difference between age groups (Mann-Whitney $U$ test, $Z=-0.641, p=0.522$ ). As shown in Figure $6 H$, normalized rate differences on remapped days $(0.760 \pm 0.011)$ were significantly higher than those on stable days $(0.289 \pm 0.021$; paired $t$ test: $t_{(5)}=-15.06, p<0.001$, tested within the six rats that remapped). Average normalized rate differences negatively and significantly correlate with average spatial correlation scores for each day (Fig. 6I, Pearson correlation, $r=-0.9162, p<$ 0.0001).

The incidences of spontaneous remapping were not distributed evenly over training sessions. Strikingly, remapping was not observed in any rat until day 14 of training; before this day there were few spatially unstable cells in the recorded sample. Table 2 shows days on which remapping occurred in individual rats. Two of six young rats and four of six old rats remapped on at least one day of the experiment ("remapping rats"). Figure 8 shows these data for each age group in a frequency histogram. Chisquare analysis determined that there is no difference in the distribution of remapping rats between age groups $\left(\chi^{2}(1)=2.396\right.$, $p=0.122)$, although the low number of observations precludes a definitive conclusion (Fisher's Exact test also indicated no significant difference; $p=0.175$ ). Considering only those rats that remapped at least once, the average chance of remapping in this sample of rats was $46.8 \%$ from the onset of remapping to day 31 of conditioning (see Table 2 for range).

Does spontaneous remapping result in a failure to retrieve memories of correct blink locations for spatial cues in the environment? An "eyeblink change" score was calculated for each rat on each day of training by subtracting Session 1 eyeblink conditioning scores (percent EMG above threshold during the last $4 \mathrm{~cm}$ before the stimulus position) from those in Session 2. If remapping resulted in degraded performance, a large score (positive or negative) would be expected on that day. The majority of eyeblink change scores were small in both age groups and at both stimulus positions on days in which the hippocampal map re- 
Table 1. Control parameters for spatial eyeblink conditioning and CA1 unit recordings on stable versus remapped days of experiment

\begin{tabular}{|c|c|c|c|}
\hline & Stable days ( $n=12$ rats) & Remapped days ( $n=6$ rats) & Stable versus remapped \\
\hline Duration of rest in home cage (min) & 157.233 .99 & 148.8610 .02 & Wilcoxon Signed Ranks Test, $Z=-0.734, p=0.463$ \\
\hline Length of conditioning session 1 (min) & 22.662 .75 & 22.33 .09 & Paired $t$ test, $t_{(5)}=-0.150, p=0.887$ \\
\hline Length of conditioning session 2 (min) & 20.942 .48 & 24.793 .4 & Paired $t$ test, $t_{(5)}=2.164, p=0.083$ \\
\hline No. units recorded per day & 42.854 .05 & 51.517 .3 & Paired $t$ test, $t_{(5)}=0.786, p=0.467$ \\
\hline
\end{tabular}

Table 2. Frequency of CA1 spontaneous remapping during $31 \mathrm{~d}$ of spatial eyeblink conditioning

\begin{tabular}{|c|c|c|c|c|}
\hline Rat & Age group & Days of experiment that rat remapped & Days of total experiment remapped (\%) & Days remapped after remapping onset (\%) \\
\hline 8419 & Young & $14,20,23,24,28$ & 16.1 & 27.8 \\
\hline 8570 & Young & None & 0 & N/A \\
\hline 8645 & Young & None & 0 & $\mathrm{~N} / \mathrm{A}$ \\
\hline 8646 & Young & None & 0 & $\mathrm{~N} / \mathrm{A}$ \\
\hline 8820 & Young & $16,19,24,31$ & 12.9 & 25.0 \\
\hline 8957 & Young & None & 0 & N/A \\
\hline 8417 & Old & 29,31 & 6.5 & 66.7 \\
\hline 8564 & Old & None & 0 & N/A \\
\hline 8700 & Old & $28,29,31$ & 9.7 & 75 \\
\hline 8778 & Old & None (no data past day 15) & 0 & N/A \\
\hline 8886 & Old & $14,15,17,18,19,20,21,24,25,26,28,29,30$ & 41.9 & 72.2 \\
\hline \multirow[t]{2}{*}{8981} & Old & 18,31 & 6.5 & 14.3 \\
\hline & & Average remapped (\%) & 7.8 & 46.8 \\
\hline
\end{tabular}

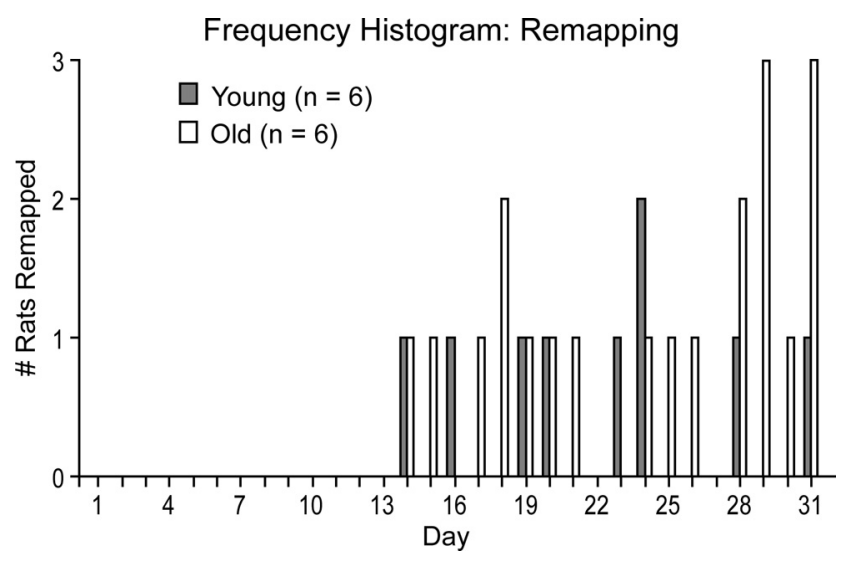

Figure 8. Time course of remapping in young and old rats during spatial eyeblink conditioning. The first observations of remapping in this sample of young and old rats occurred on day 14 of training; on this day, of a possible six young and six old rats, one young rat and one old rat remapped. As training continued, remapping was observed again on some days in the same rats, and four additional rats later remapped as well (see Table 2 for data from individual rats). By training day 31, two young rats and four old rats had remapped on at least one day of the experiment.

mained spatially stable between sessions (Fig. 9A-D). A similar pattern was observed on the remapped days; most eyeblink change scores were not large in value as would be predicted if remapping led to loss of spatial precision of the conditioned blink.

\section{Study 3: Morris water task and relationships between hippocampal map stability and behavior}

The next consideration was whether there is any relationship between age, remapping, and spatial memory in the Morris water task. Aged rats were significantly impaired in learning the location of the submerged platform as compared to the young rats (mean CIPL of last 6 trials: young, $85.0 \pm 41.3$; aged, $312.0 \pm$ 49.5; Mann-Whitney $U$ test: $Z=-2.56, p=0.01$ ).
Although there are age-related changes in performance on the Morris water task, only a minor age effect in the unconditioned running direction was found in the spatial eyeblink task, with no significant age difference in learning the locations of the blink positions approached from the conditioned running direction (Fig. 4). We hypothesized that hippocampal map stability, in addition to age, may be an important variable in determining behavioral performance on these tasks. Thus, for further analyses rats were then separated into two groups by stability of their hippocampal maps during the spatial eyeblink task rather than by age. These groups were "Remapping Rats" $(n=6)$ that exhibited spontaneous CA1 remapping on at least one day of the experiment, and "Stable Rats" ( $n=5$; one rat did not reach the end of the training period and was not assigned to either group) that exhibited spatially stable CA1 firing patterns on every day of the experiment.

Indeed, the hypothesis that there may be behavioral differences between remapping and non-remapping rats is confirmed. Considering spatial memory performance on the Morris water task, stable rats performed significantly better (with lower CIPL scores and higher water maze index scores) on the last six spatial trials of the Morris water task than did remapping rats (Fig. 10A; mean CIPL of last six trials: stable rats, $55.8 \pm 21.6$; remapping rats, $285.2 \pm 56.6$; Student's $t$ test for CIPL: $t_{(9)}=3.50, p=0.007$; Student's $t$ test for water maze index: $t_{(6.39)}=3.888, p=0.007$, equal variances not assumed).

An index of spatial eyeblink conditioning was also calculated for each rat by averaging their percent EMG above threshold during the last $4 \mathrm{~cm}$ of approach to positions 1 and 2 during the last 5 days of training (Fig. 10B). Remapping rats had significantly higher spatial eyeblink scores than did stable rats (Mann-Whitney $U$ test: $Z=-2.56, p=0.011, n=11)$, indicating that rats that learned the locations of the blink stimuli the best were more likely to exhibit CA1 remapping at some time during the 31 days of training. The scores of individual stable and remapping rats on the water task and spatial eyeblink conditioning were not significantly related, as shown in Figure $10 \mathrm{C}$. Considering all rats to- 
A

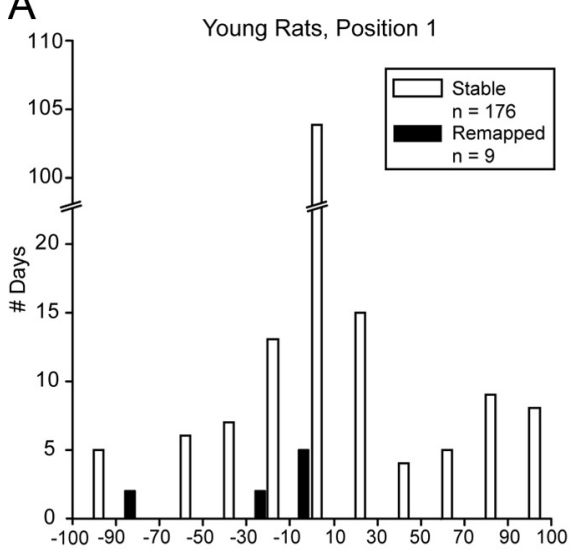

C

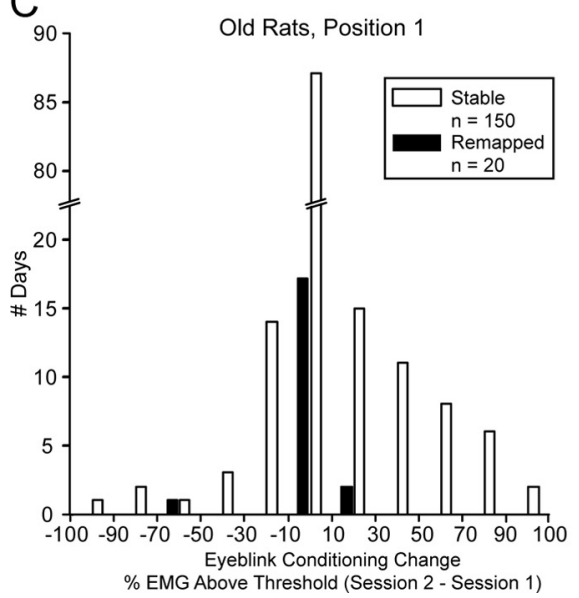

B

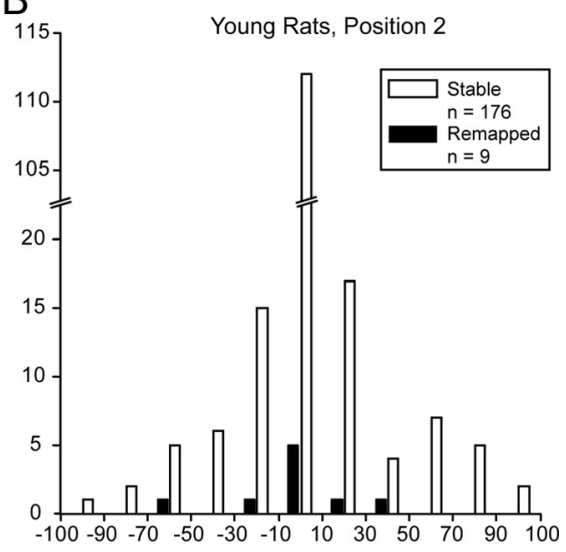

$D$

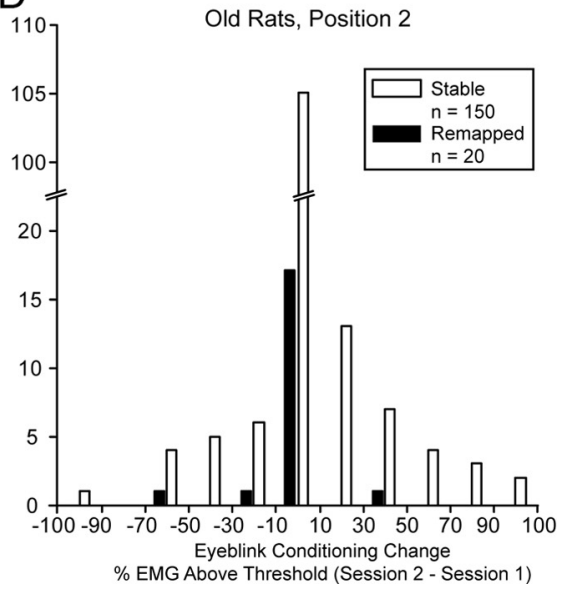

Figure 9. Remapping does not result in the loss of spatially precise place conditioning. Blink scores during the last $4 \mathrm{~cm}$ of the approach to the blink positions of Session 1 were subtracted from those of Session 2 for each rat on each day; this calculation produced Eyeblink Conditioning Change scores ranging from -100 to +100 , with a score of 0 indicating no change between sessions and scores near -100 or +100 indicating that conditioning was good in one session but poor in the other. These data are shown in frequency histograms in which the number of spatially stable and remapped days was tabulated for each possible eyeblink conditioning change. $\boldsymbol{A}, \boldsymbol{B}$, At eyeblink positions 1 and 2, young rats showed little difference between Session 1 and Session 2 eyeblink conditioning scores on most days in which the hippocampal map was spatially stable. $\boldsymbol{C}, \boldsymbol{D}$, A similar pattern was observed in old rats at positions 1 and 2. On most days in which remapping occurred, young and old rats also exhibited similar levels of place conditioning between Session 1 and Session 2.

gether, the water task and spatial eyeblink scores are inversely, but not significantly, related $\left(r_{(9)}=-0.51, p=0.11\right)$.

The spatial eyeblink conditioning learning curve for stable and remapping rats reveals that during the first few days of training, remapping rats increased blinking at positions 1 and 2 more rapidly than did stable rats (Fig. 10D). Blinking continued to slowly increase over the first 3 weeks of training, although there was a significant effect of training over all days for remapping rats but not for stable rats (Friedman test: remapping rats, $\chi^{2}(61)=134.09, p<0.0001$; stable rats, $\chi^{2}(61)=70.2, p=$ $0.197)$.

Do other changes in the CA1 map, which could explain the small difference in blinking in the unconditioned direction found in old rats at Position 1 (Fig. 4C,E), develop as rats learn the blink locations? Studies in a modified version of the water maze task (Hollup et al., 2001) and in a cheeseboard task in which spatial locations were learned (Dupret et al., 2010) have shown that place field density can increase at goal locations. To assess whether cells developed a greater density of place fields at each stimulus position as rats acquired the blink response, cells with fields within 15 $\mathrm{cm}$ of positions 1 and 2 were examined during the training inter- vals of days 1-10, 11-20, and 21-30 (Table 3). This analysis was motivated by the hypothesis that cells may "add" place fields near the stimulus locations to their firing patterns during acquisition of spatial eyeblink conditioning, resulting in an increase of cells with multiple place fields near the stimulus locations. At Position 1, there was a significant effect of age collapsed over all training intervals, with young rats having a greater proportion of cells with multiple fields than did old rats (repeated-measures ANOVA, $F_{(1,9)}=$ $18.4, p=0.002)$. When rats were separated into stable and remapping groups instead, the stable group exhibited a greater proportion of cells with multiple fields than did the remapping group (repeated-measures ANOVA, $F_{(1,9)}=$ $7.25, p=0.025)$. There was no significant effect of training across the 10 day intervals.

At Position 2, there was no significant difference between the two age groups $\left(F_{(1,9)}=3.68, p=0.087\right)$ or hippocampal stability groups $\left(F_{(1,9)}=1.24, p=0.294\right)$, and no significant effect over training intervals. The restriction of the age and stability group differences to Position 1 is consistent with the age difference in eyeblink conditioning at that position, with aged rats blinking more in the unconditioned direction than did young rats.

\section{Discussion}

Four primary findings emerge from the experiments reported here: (1) confirmation that hippocampal spontaneous remapping occurs more frequently later in the lifespan (Barnes et al., 1997); (2) during an initially novel place conditioning task, remapping emerges only after at least 2 weeks of bi-daily training sessions; (3) although spatial memory measured using the Morris water task is impaired in old rats, there is no effect of age on spatial eyeblink conditioning; (4) place field stability correlated positively with water maze learning and negatively with spatial conditioning. At least two interpretations may combine to explain these results: (1) the hippocampus has a time-limited role in spatial eyeblink conditioning; (2) because poor hippocampus-dependent learning correlates with more remapping in aged rats, yet these animals exhibit good place conditioning, older rats may use behavioral strategies that rely less on the hippocampus and more on other structures that can sustain this behavior.

Here, spontaneous remapping was observed in four of six old rats and two of six young adult rats, and the locations of place fields matched less precisely between recording sessions in old rats compared to young rats. These findings are consistent with Barnes et al. (1997) in which ensembles of CA1 pyramidal cells remapped in six of six old rats and one of six young adult rats when they were familiar with the environment. Also, McNaughton et al. (1996) observed remapping in one young rat between separate recordings on a track that it had over a week of 
prior experience with, and Hok et al. (2012) reported remapping in two of four middle-aged rats and one of four aged rats in an open field environment in which they had at least 10 days of experience.

Why does spontaneous remapping occur only when rats are familiar with the environment? One possibility is that attention modulates the hippocampal population code for space. High levels of spatial attention promote stability of the mouse CA1 map, although place fields are generally less stable in mice than in rats (Kentros et al., 2004; Muzzio et al., 2009). The absence of remapping early in training might result from higher levels of vigilance compared to when rats have become overtrained. Alternately, in some situations the hippocampal CA1 population code can undergo tuning on a similar time course to that of the remapping onset observed here. Lever et al. (2002) showed that CA1 representations of similar circleshaped versus square-shaped boxes took days or weeks to develop (Leutgeb et al., 2005). Although this observation was made under different conditions from those of the present study, both results suggest that the CA1 map may undergo a period of refinement that occurs during the first few days or weeks in a new context.

What is the hippocampal role in spatial eyeblink conditioning? Hippocampal lesions significantly impair trace eyeblink conditioning (Kim et al., 1995), and during acquisition of both trace and delay eyeblink conditioning, CA1 pyramidal neurons adjust their firing patterns at specific time intervals such as after conditioned stimulus (CS; tone) or unconditioned stimulus (US; air puff) presentation (for review, Christian and Thompson, 2003). Although lesion studies have demonstrated that the hippocampus is not required for successful delay conditioning, the medial temporal lobe memory system may be required for declarative memory of delay conditioning (Weiskrantz and Warrington, 1979) and for conditional discrimination and discrimination reversal eyeblink conditioning paradigms (Berger and Orr, 1983; Daum et al., 1991). Because the spatial eyeblink task requires information regarding the current location of the rat, which is represented by the activity patterns of ensembles of hippocampal neurons, it is likely that the hippocampus participates in mediating the behavioral response. Further evidence for hippocampal involvement in this task emerges from old rats blinking more in the unconditioned running direction at Position 1, indicating impairment in learning the direction specificity of the task, and having fewer multiple place fields near this blink location. Considering that Dupret et al. (2010) found that CA1 place fields increase in density near target sites as these locations are learned, one interpretation of the present data is that in old rats place fields do not reorganize to represent the blink location as extensively as occurs in young rats. These findings suggest a hippocampal role in directional tuning of the blink response
Spatial Eyeblink Conditioning Mean of Last 5 Days, Positions 1 and 2
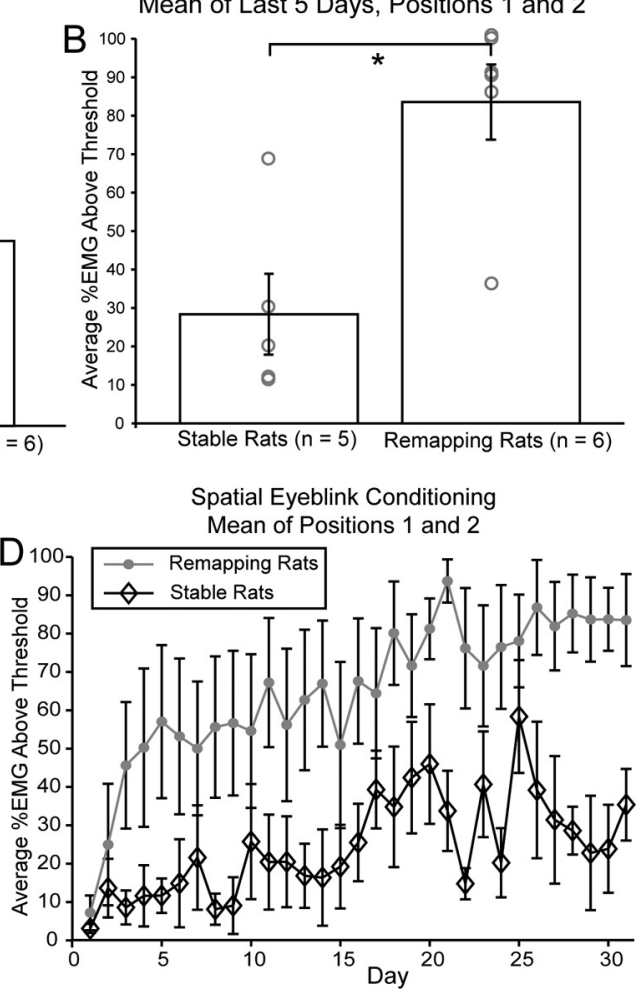

Figure 10. Relatively impaired spatial memory but good eyeblink conditioning to place in rats that spontaneously remap. Rats ping Rats), and those that exhibited spatial stability of the CA1 map between the two sessions of every day of the experiment Rats). $\boldsymbol{A}$, Individual water maze index scores (higher scores indicate more efficient paths to the hidden platform) on the las Spatial eyeblink conditioning scores during the last 5 days of the experime table Rats. C, Individual scores of stable and remapping rats during the last six trials of the Morris water task and the last 5 days of throughout training but lacked a period of rapid acquisition early in training. For statistics, see Study 3: Morris water task, Results. Asterisks indicate $p<0.05$.

and a deficit in old rats to separate context codes for each running direction (McNaughton et al., 1983a; Gothard et al., 1996; Rosenzweig and Barnes, 2003).

Additionally, critical information for spatial eyeblink conditioning may be stored outside the hippocampus during the overtraining period. Trace eyeblink conditioning has been shown to initially rely on the hippocampus, becoming increasingly hippocampus independent once performance plateaus (for review, Christian and Thompson, 2003; Clark, 2011). Hippocampal lesions impair trace eyeblink conditioning shortly, but not 1 month, after acquisition (Kim et al., 1995), whereas medial prefrontal cortex lesions have little effect on trace memory one day after training but elicit a larger impairment 2 and 4 weeks after training (Takehara et al., 2003; Takehara-Nishiuchi and McNaughton, 2008). Thus, the information required to evoke the eyeblink response at the appropriate time may initially be provided by the hippocampus but later by the medial prefrontal cortex. In the present study, a similar shift of information storage from hippocampus to other cortical areas could explain the maintenance of spatial eyeblink accuracy after the onset of spontaneous remapping.

Further insight into the time course of hippocampal involvement in spatial eyeblink conditioning might be provided by stud- 


\begin{tabular}{|c|c|c|c|c|}
\hline & Young & Old & Stable & Remapping \\
\hline \multicolumn{5}{|l|}{ Position 1} \\
\hline Days 1-10 & $64.4 \pm 5.29$ & $59.71 \pm 3.99$ & $61.26 \pm 6.9$ & $63.11 \pm 2.92$ \\
\hline Days 11-20 & $76.03 \pm 5.38$ & $44.44 \pm 7.28$ & $75.47 \pm 7.18$ & $50.18 \pm 7.91$ \\
\hline Days 21-30 & $69.33 \pm 4.73$ & $54.84 \pm 3.0$ & $72.54 \pm 4.42$ & $54.59 \pm 2.27$ \\
\hline \multicolumn{5}{|l|}{ Position 2} \\
\hline Days 1-10 & $57.24 \pm 5.56$ & $38.82 \pm 5.75$ & $54.0 \pm 7.62$ & $44.58 \pm 6.09$ \\
\hline Days $11-20$ & $65.86 \pm 9.41$ & $41.56 \pm 7.25$ & $54.67 \pm 12.96$ & $54.94 \pm 8.08$ \\
\hline Days $21-30$ & $46.12 \pm 5.46$ & $47.33 \pm 12.38$ & $56.3 \pm 10.11$ & $38.65 \pm 5.98$ \\
\hline
\end{tabular}

Data are shown across age groups and across map stability categories. All young rats, $n=6$ and all old rats, $n=6 ;$ stable rats that did not spontaneously remap, $n=5$; and remapping rats that did remap on at least 1 day during spatia eyeblink condition, $n=6$. For Position 1 , both old rats and remapping rats had significantly fewer place fields per cell than did young and stable rats.

ies of rabbit CA1 activity patterns in trace conditioning. In general, firing rates increase during acquisition in time intervals immediately following CS or US presentation or during the trace interval (McEchron and Disterhoft, 1997; McEchron et al., 2001). Firing rate changes and increased CA1 neuron excitability are observed during acquisition, but once stable performance is achieved, activity patterns begin to return to baseline levels (Moyer et al., 1996; McEchron and Disterhoft, 1997). Taken together with the present study, these data suggest that hippocampal involvement in spatial eyeblink conditioning might be strongest during acquisition and then decline between training days 10 and 20 as the blink response stabilizes.

Is remapping a factor in memory impairment? Rats with the most impaired spatial memory, as assessed by the Morris swim task, remapped the most. But by day 14 rats that remapped showed accurate place conditioning, whereas rats that did not remap showed no significant improvement over time in eyeblink conditioning. This difference in learning suggests that stable and remapping rats may learn the spatial eyeblink task by using different behavioral strategies that engage distinct or only partially overlapping neural systems. These might include a stimulusresponse strategy in which rats count steps from the food reward to locate the blink stimulus, and a cue-based learning strategy in which a stimulus location is associated with a single cue rather than within the context of the room. Alternatively, Rudy (2009) suggests that the perirhinal and postrhinal cortices can support some contextual functions with extensive training and may mediate contextual fear conditioning when the hippocampus is not available functionally (Lehmann et al., 2009). Fanselow (2010) proposes that in the absence of the hippocampus-dependent contextual learning system, a less efficient configural learning system can be employed. These ideas raise the possibility that overtraining on the spatial eyeblink conditioning task allowed an alternate system to be engaged.

The related idea that active competition between neural systems for a given task solution can occur and can result in the domination of one system over others (Fanselow, 2010) is consistent with the outcome of the present experiment. In spatial eyeblink conditioning the hippocampus-dependent spatial learning system may dominate task solution for some rats, but for others (such as those that remap) a hippocampus-independent system may take control. In fact, lack of an age difference in place conditioning is consistent with the idea that most aged rats might use a hippocampus-independent strategy. Similarly, Barnes et al. (1980) found that when place, response, and cue learning strategies were available for solution of a T-maze problem, aged rats used a response strategy more often than place or cue strategies, whereas young adults used a place learning strategy most often.

Considering that remapping does not result in impaired place conditioning under these experimental conditions and that rats that remap show hippocampus-dependent spatial memory impairment, we suggest that hippocampus-independent systems take on a greater role in memory tasks when hippocampal function is weak. This hypothesis is consistent with the results of human neurocognitive studies that show reduced activity in medial temporal lobe areas during memory tasks in older adults (Grady et al., 1995; Cabeza et al., 2004) and that bilateral activation of these structures, or increased activity in other specific brain regions (e.g., the prefrontal cortex), is associated with better performance (Cabeza et al., 2002; Maguire and Frith, 2003; Grady, 2008). For example, Grady $(1998,2008)$ argues that distributed networks of neural activity are altered during aging such that function and/or efficiency is reduced and that new networks may be recruited to compensate (Stern, 2002; Stern, 2009; Park and Reuter-Lorenz, 2009). Within this framework, the results of the present study suggest that information transfer between neural systems that support task-specific behavioral strategies can differ between animals within and across age groups, with animals of advanced age showing a shift away from functional engagement of the hippocampus.

\section{References}

Barnes CA, Nadel L, Honig WK (1980) Spatial memory deficit in senescent rats. Can J Psychol 34:29-39. CrossRef Medline

Barnes CA, Danysz W, Parsons CG (1996) Effects of the uncompetitive NMDA receptor antagonist memantine on hippocampal long-term potentiation, short-term exploratory modulation and spatial memory in awake, freely moving rats. Eur J Neurosci 8:565-571. CrossRef Medline

Barnes CA, Suster MS, Shen J, McNaughton BL (1997) Multistability of cognitive maps in the hippocampus of old rats. Nature 388:272-275. CrossRef Medline

Berger TW, Orr WB (1983) Hippocampectomy selectively disrupts discrimination reversal conditioning of the rabbit nictitating membrane response. Behav Brain Res 8:49-68. CrossRef Medline

Burke SN, Barnes CA (2008) Aging ensembles circuit contributions to memory deficits. In: Hippocampal place fields (Mizumori, SJY, ed), pp 364-410. Oxford: Oxford UP.

Cabeza R, Anderson ND, Locantore JK, McIntosh AR (2002) Aging gracefully: compensatory brain activity in high-performing older adults. Neuroimage 17:1394-1402. CrossRef Medline

Cabeza R, Daselaar SM, Dolcos F, Prince SE, Budde M, Nyberg L (2004) Task-independent and task-specific age effects on brain activity during working memory, visual attention and episodic retrieval. Cereb Cortex 14:364-375. CrossRef Medline

Christian KM, Thompson RF (2003) Neural substrates of eyeblink conditioning: acquisition and retention. Learn Mem 10:427-455. CrossRef Medline

Clark RE (2011) Eyeblink conditioning and systems consolidation: An ironic yet powerful pairing. Neurobiol Learn Mem 95:118-124. CrossRef Medline

Colgin LL, Moser EI, Moser MB (2008) Understanding memory through 
hippocampal remapping. Trends Neurosci 31:469-477. CrossRef Medline

Daum I, Channon S, Polkey CE, Gray JA (1991) Classical conditioning after temporal lobe lesions in man: Impairment in conditional discrimination. Behav Neurosci 105:396-408. CrossRef Medline

Dupret D, O’Neill J, Pleydell-Bouverie B, Csicsvari J (2010) The reorganization and reactivation of hippocampal maps predict spatial memory performance. Nat Neurosci 13:995-1002. CrossRef Medline

Fanselow MS (2010) From contextual fear to a dynamic view of memory systems. Trends Cogn Sci 14:7-15. CrossRef Medline

Gallagher M, Burwell R, Burchinal M (1993) Severity of spatial learning impairment in aging: development of a learning index for performance in the Morris water maze. Behav Neurosci 107:618-626. CrossRef Medline

Gerrard JL, Kudrimoti H, McNaughton BL, Barnes CA (2001) Reactivation of hippocampal ensemble activity patterns in the aging rat. Behav Neurosci 115:1180-1192. CrossRef Medline

Gothard KM, Skaggs WE, McNaughton BL (1996) Dynamics of mismatch correction in the hippocampal ensemble code for space: Interaction between path integration and environmental cues. J Neurosci 16:8027-8040. Medline

Grady CL (1998) Brain imaging and age-related changes in cognition. Exp Gerontol 33:661-673. CrossRef Medline

Grady CL (2008) Cognitive neuroscience of aging. Ann N Y Acad Sci 1124: 127-144. CrossRef Medline

Grady CL, McIntosh AR, Horwitz B, Maisog JM, Ungerleider LG, Mentis MJ, Pietrini P, Schapiro MB, Haxby JV (1995) Age-related reductions in human recognition memory due to impaired encoding. Science 269:218221. CrossRef Medline

Green JT, Arenos JD (2007) Hippocampal and cerebellar single-unit activity during delay and trace eyeblink conditioning in the rat. Neurobiol Learn Mem 87:269-284. CrossRef Medline

Henriksen EJ, Colgin LL, Barnes CA, Witter MP, Moser MB, Moser EI (2010) Spatial representation along the proximodistal axis of CA1. Neuron 68:127-137. CrossRef Medline

Hill AJ (1978) First occurrence of hippocampal spatial firing in a new environment. Exp Neurol 62:282-297. CrossRef Medline

Hok V, Chah E, Reilly RB, O’Mara SM (2012) Hippocampal dynamics predict interindividual cognitive differences in rats. J Neurosci 32:35403551. CrossRef Medline

Hollup SA, Molden S, Donnett JG, Moser MB, Moser EI (2001) Accumulation of hippocampal place fields at the goal location in an annular watermaze task. J Neurosci 21:1635-1644. Medline

Kentros CG, Agnihotri NT, Streater S, Hawkins RD, Kandel ER (2004) Increased attention to spatial context increases both place field stability and spatial memory. Neuron 42:283-295. CrossRef Medline

Kim JJ, Clark RE, Thompson RF (1995) Hippocampectomy impairs the memory of recently, but not remotely, acquired trace eyeblink conditioned responses. Behav Neurosci 109:195-203. CrossRef Medline

Kubie JL, Fenton A, Novikov N, Touretzky D, Muller RU (2007) Changes in goal selection induced by cue conflicts are in register with predictions from changes in place cell field locations. Behav Neurosci 121:751-763. CrossRef Medline

Lehmann H, Sparks FT, Spanswick SC, Hadikin C, McDonald RJ, Sutherland RJ (2009) Making context memories independent of the hippocampus. Learn Mem 16:417-420. CrossRef Medline

Lenck-Santini PP, Save E, Poucet B (2001) Evidence for a relationship between place-cell spatial firing and spatial memory performance. Hippocampus 11:377-390. CrossRef Medline

Leutgeb JK, Leutgeb S, Treves A, Meyer R, Barnes CA, McNaughton BL, Moser MB, Moser EI (2005) Progressive transformation of hippocampal neuronal representations in "morphed" environments. Neuron 48: 345-358. CrossRef Medline

Leutgeb S, Leutgeb JK, Moser EI, Moser MB (2006) Fast rate coding in hippocampal CA3 cell ensembles. Hippocampus 16:765-774. CrossRef Medline

Lever C, Wills T, Cacucci F, Burgess N, O’Keefe J (2002) Long-term plasticity in hippocampal place-cell representation of environmental geometry. Nature 416:90-94. CrossRef Medline

Maguire EA, Frith CD (2003) Aging affects the engagement of the hippocampus during autobiographical memory retrieval. Brain 126:1511-1523. CrossRef Medline

Markus EJ, Qin YL, Leonard B, Skaggs WE, McNaughton BL, Barnes CA (1995) Interactions between location and task affect the spatial and di- rectional firing of hippocampal neurons. J Neurosci 15:7079-7094. Medline

McEchron MD, Disterhoft JF (1997) Sequence of single neuron changes in CA1 hippocampus of rabbits during acquisition of trace eyeblink conditioned responses. J Neurophysiol 78:1030-1044. Medline

McEchron MD, Weible AP, Disterhoft JF (2001) Aging and learningspecific changes in single-neuron activity in CA1 hippocampus during rabbit trace eyeblink conditioning. J Neurophysiol 86:1839-1857. Medline

McNaughton BL, Barnes CA, O'Keefe J (1983a) The contributions of position, direction, and velocity to single unit activity in the hippocampus of freely moving rats. Exp Brain Res 52:41-49. Medline

McNaughton BL, O'Keefe J, Barnes CA (1983b) The stereotrode: a new technique for simultaneous isolation of several single units in the central nervous system from multiple unit records. J Neurosci Meth 8:391-397. CrossRef Medline

McNaughton BL, Barnes CA, Gerrard JL, Gothard K, Jung MW, Knierim JJ, Kudrimoti H, Qin Y, Skaggs WE, Suster M, Weaver KL (1996) Deciphering the hippocampal polyglot: the hippocampus as a path integration system. J Exp Biol 199:173-185. Medline

Morris RG (1984) Developments of a water-maze procedure for studying spatial learning in the rat. J Neurosci Meth 11:47-60. CrossRef Medline

Moser EI, Kropff E, Moser MB (2008) Place cells, grid cells, and the brain's spatial representation system. Annu Rev Neurosci 31:69-89. CrossRef Medline

Moyer JR Jr, Thompson LT, Disterhoft JF (1996) Trace eyeblink conditioning increases CA1 excitability in a transient and learning-specific manner. J Neurosci 16:5536-5546. Medline

Moyer JR Jr, Power JM, Thompson LT, Disterhoft JF (2000) Increased excitability of aged rabbit CA1 neurons after trace eyeblink conditioning. J Neurosci 20:5476-5482. Medline

Muzzio IA, Levita L, Kulkarni J, Monaco J, Kentros C, Stead M, Abbott LF, Kandel ER (2009) Attention enhances the retrieval and stability of visuospatial and olfactory representations in the dorsal hippocampus. PLoS Biol 7:e1000140. CrossRef Medline

O'Keefe J, Nadel L (1978) The hippocampus as a cognitive map. Oxford: Oxford UP.

O'Keefe J, Speakman A (1987) Single unit activity in the rat hippocampus during a spatial memory task. Exp Brain Res 68:1-27. Medline

Park DC, Reuter-Lorenz P (2009) The adaptive brain: aging and neurocognitive scaffolding. Annu Rev Psychol 60:173-196. CrossRef Medline

Recce M, O'Keefe J (1989) The tetrode: a new technique for multi-unit extracellular recording. Soc Neurosci Abstr 15:1250.

Rosenzweig ES, Barnes CA (2003) Impact of aging on hippocampal function: plasticity, network dynamics, and cognition. Prog Neurobiol 69: 143-179. CrossRef Medline

Rosenzweig ES, Redish AD, McNaughton BL, Barnes CA (2003) Hippocampal map realignment and spatial learning. Nat Neurosci 6:609615. CrossRef Medline

Rudy JW (2009) Context representations, context functions, and the parahippocampal-hippocampal system. Learn Mem 16:573-585. CrossRef Medline

Shen J, Barnes CA (1996) Age-related decrease in cholinergic synaptic transmission in three hippocampal subfields. Neurobiol Aging 17:439-451. CrossRef Medline

Shen J, Barnes CA, McNaughton BL, Skaggs WE, Weaver KL (1997) The effect of aging on experience-dependent plasticity of hippocampal place cells. J Neurosci 17:6769-6782. Medline

Stern Y (2002) What is cognitive reserve? Theory and research application of the reserve concept. J Int Neuropsych Soc 8:448-460. CrossRef

Stern Y (2009) Cognitive reserve. Neuropsychologia 47:2015-2028. CrossRef Medline

Takehara K, Kawahara S, Kirino Y (2003) Time-dependent reorganization of the brain components underlying memory retention in trace eyeblink conditioning. J Neurosci 23:9897-9905. Medline

Takehara-Nishiuchi K, McNaughton BL (2008) Spontaneous changes of neocortical code for associative memory during consolidation. Science 322:960-963. CrossRef Medline

Thompson LT, Best PJ (1990) Long-term stability of the place-field activity of single units recorded from the dorsal hippocampus of freely behaving rats. Brain Res 509:299-308. CrossRef Medline 
Weiskrantz L, Warrington EK (1979) Conditioning in amnesic patients. Neuropsychologia 17:187-194. CrossRef Medline
Wilson MA, McNaughton BL (1993) Dynamics of the hippocampal ensemble code for space. Science 261:1055-1058. CrossRef Medline 